\title{
IAMS08 Calls for Advanced Materials Industry Responsibility and Development
} www.chemevent.com.cn/IAMS08_en

The 2nd International Advanced Materials (Tianjin) Summit (IAMS08), held in Tianjin from October 30 to November 1, 2008 , focused on opportunities and responsibilities of the chemical and commodity materials sector in the declining global economy.

Opportunities in the innovation, research and development, and application of new chemical materials, and in aerospace craft materials and water resources as well as in energy efficiencies, were discussed by about 300 attendees consisting of government officials, experts, corporate leaders, and investors.

"New chemical materials have a bright future in spite of the recent softer demand in the domestic market," said Jianxin Ren, director of the China National Chemical Corporation (ChemChina); "[The] Chinese government has taken a series of measures to spur economic growth, including supporting agricultural development, cutting deposit and lending interest rates, and reducing export rebate rates. These moves will help push the development of new chemical materials."

During the panel discussion on "Opportunity \& Investment Strategy," Weiming Jiang, president of DSM China, pointed out the important role that China plays amid the global financial crisis. China will provide opportunities for the development of new chemical materials in many industries such as environmental protection, high speed bullet trains, wind energy, and large airplanes.

Michael Koenig, president of Bayer MaterialScience, said that his company can help address the current climate problems to achieve a more sustainable future by boosting the energy efficiency

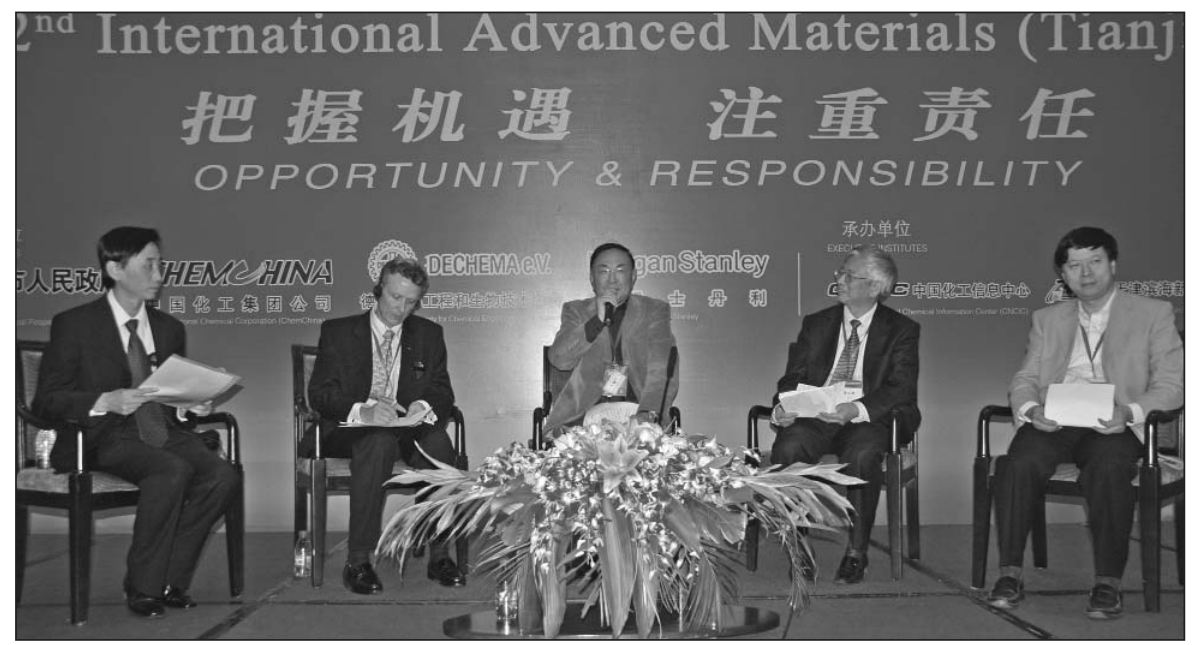

During the second International Advanced Materials (Tianjin) Summit (IAMS08), held in Tianjin from October 30 to November 1, 2008, academics serve as panelists in a discussion about advanced materials science and technology.

of buildings or products, or by promoting the use of environmentally responsible products for its customers.

What is the global direction in materials research and innovation? Alan J. Hurd of Los Alamos National Laboratory, USA, and former president of the Materials Research Society, reminded attendees of the New Growth Theory in economics. Innovations have accounted for a substantial portion of the modern quality of life, and materials have played a major role. "The greatest obligation of scientists, engineers, and inventors," Hurd said, "is clearly in energy technologies." All current and prior energy technologies derive from materials successes, such as high-strength steel in generators and engines, light-weight materials for aircraft, and concrete for hydroelectric dams. Future energy sources, storage, and transmission will rely on materials breakthroughs, he said. Speakers in the panel on "Professor Lecture" further discussed materials in daily life and predicted the future of advanced materials.

The Advanced Materials Industry Advocacy proclamation in the closing ceremony calls for social responsibility for industrial innovation, energy-savings, and environmentally friendly development.

IAMS08 was endorsed by the Materials Research Society.

TinA Hu

IAMS08 Organizing Committee

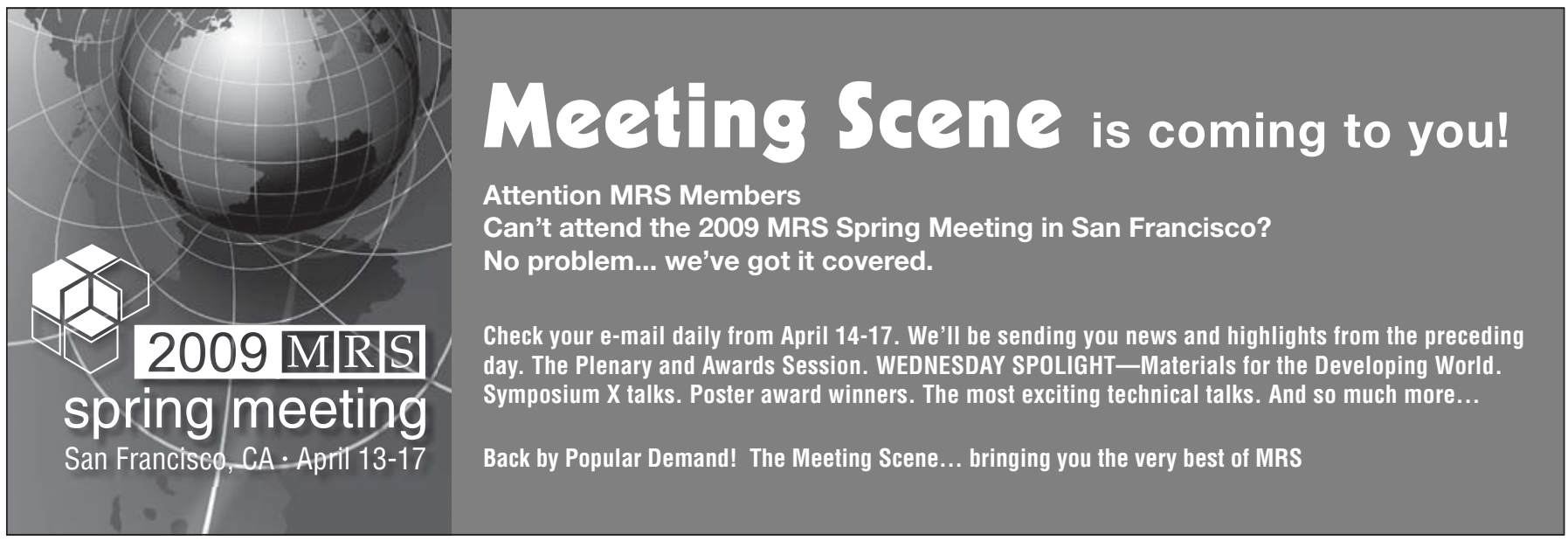

